\title{
Pulmonary obstruction in individuals with cervical spinal cord lesions unmasked by bronchodilator administration
}

\author{
A M Spungen MS, ${ }^{1-3} \mathrm{P}$ V Dicpinigaitis MD,${ }^{2,4} \mathrm{P}$ L Almenoff MD, ${ }^{1,2,4}$ \\ W A Bauman $\mathrm{MD}^{1-3}$ \\ ${ }^{1}$ Spinal Cord Damage Research Center, SCI and Medical Services, Veterans Affairs \\ Medical Center, 130 West Kingsbridge Road, Bronx, New York 10468, The Mount Sinai \\ Medical Center, and The Mount Sinai School of Medicine; ${ }^{2}$ Department of Medicine; \\ ${ }^{3}$ Department of Rehabilitation Medicine; ${ }^{4}$ Division of Pulmonary/Critical Care Medicine, \\ New York 10029, USA.
}

In subjects with spinal cord injury (SCI) a restrictive ventilatory impairment has been well described. Despite numerous studies of pulmonary function in patients with SCI, evidence of an obstructive component of respiratory dysfunction as a result of paralysis has not been observed in this population. We performed spirometry in 34 patients with cervical SCI before and after administration of an inhaled bronchodilator. Significant improvement in flow rate was demonstrated in $14(41 \%)$ subjects. Our results suggest that transection of the cervical spine may result in obstruction to air flow, possibly due to interruption of the sympathetic innervation of the lung with resultant unopposed parasympathetic tone producing bronchoconstriction.

Keywords: quadriplegia; spinal cord injury; pulmonary obstruction; ventilatory impairment; bronchodilator.

\section{Introduction}

The degree of respiratory impairment resulting from traumatic injury to the spinal cord is dependent upon the level of injury sustained. Lesions above the third cervical level result in total paralysis of all muscles of respiration, and thereby necessitate mechanical ventilation. Lower lesions will partially spare those inspiratory muscles (diaphragm, scalenes, and sternomastoid) receiving cervical innervation. All muscles of expiration, which are innervated by the thoracic and lumbar spine, are rendered paralyzed by transection of the cervical cord (quadriplegia).

Pulmonary function studies in patients with quadriplegia have documented a restrictive ventilatory impairment, the severity of which parallels the level of injury. ${ }^{1}$ Spirometry and measurement of static lung volumes classically reveal significant reductions in vital capacity (VC), inspiratory capacity (IC) and expiratory reserve volume (ERV), as well as elevated residual volume (RV). Measures of air flow, such as the forced expiratory volume in 1 second
$\left(\mathrm{FEV}_{1}\right)$ and forced expiratory flow between $25 \%$ and $75 \%$ of the exhaled volume $\left(\mathrm{FEF}_{25-75 \%}\right)$, are also reduced. Because flow rates were always felt to be decreased in proportion to the reduction in $\mathrm{VC}$, the presence of an obstructive component of respiratory dysfunction in this population may not have been suspected by previous investigators. ${ }^{2-7}$

Transection of the cervical spine interrupts the sympathetic nerve supply to the lungs, which originates from the upper six thoracic ganglia, while parasympathetic innervation, arising from the vagal nuclei of the brainstem with efferent fibers incorporated into the vagus nerve which synapse in ganglia within the airway wall, remains intact. ${ }^{8}$ Such unopposed cholinergic tone accounts for the hypotension and bradycardia associated with cervical spinal cord injury (SCI) and the reported respiratory manifestation of congestion of the sinuses and upper airway, ${ }^{1}$ but may also predispose to bronchial smooth muscle constriction and, perhaps, clinically significant airway obstruction. 
To further assess the nature of the respiratory dysfunction caused by cervical SCI, we performed pulmonary function studies prior to and after the administration of an inhaled beta-adrenergic agent, metaproterenol, to a group of subjects with quadriplegia.

\section{Methods}

Thirty-four male patients with quadriplegia were recruited from the Spinal Cord Injury Service at the Bronx Veterans Administration Medical Center. The study group consisted of 12 nonsmokers (NS), defined as those who had never smoked, and 22 smokers (S), 14 of whom had stopped smoking more than one year prior to the study and 8 of whom were current smokers. The mean age ( \pm SEM) of the NS group was $40 \pm 5$ years and the mean age of the $S$ group was $48 \pm 3$ years. All 34 patients had complete motor lesions of the cervical spine, $29(85 \%)$ patients had incomplete sensory spinal cord lesions and $5(15 \%)$ had complete sensory lesions. Mean duration of injury $( \pm$ SEM) was $11.8 \pm 1.6$ years, with a range of 1-37 years. Upon questioning, 18 $(53 \%)$ patients reported dyspnea at rest or upon exertion. No subjects displayed evidence of respiratory tract infection or other acute pulmonary symptoms during the course of the study.

Pulmonary function testing was performed with the patients seated upright in their wheelchairs, using a SensorMedics dry rolling seal spirometer. Spirometry was performed before and after inhalation of $2.5 \mathrm{ml}$ metaproterenol sulfate inhalation solution $(0.6 \%)$. American Thoracic Society (ATS) guidelines for standardization of spirometry were followed. ${ }^{9}$ A significant response to the bronchodilator was defined by criteria established by the ATS as an improvement in $\mathrm{FEV}_{1} \geqslant 12 \% .{ }^{10}$ All subjects were able to complete pre- and post-bronchodilator testing.

\section{Results}

Results of pre- and post-bronchodilator (BD) spirometry for the study group are subdivided into nonsmokers (NS) and smokers (S) (Table I). Those patients desig-

Table I Pre- and post-bronchodilator (BD) spirometry assessments

\begin{tabular}{|c|c|c|c|c|c|}
\hline PFT & & Pre BD & Post BD & $\% \Delta$ & $\% \Delta$ Range \\
\hline \multicolumn{6}{|c|}{ Nonsmokers $($ responders $=5$, nonresponders $=7)$} \\
\hline $\mathrm{FEV}_{1}$ & $\mathrm{R}$ & $2.30 \pm 0.40$ & $2.63 \pm 0.43$ & $16 \pm 3$ & (12 to 26$)$ \\
\hline (1) & NR & $2.41 \pm 0.23$ & $2.42 \pm 0.23$ & $<1 \pm 1$ & $(-5$ to 11$)$ \\
\hline FVC & $\mathrm{R}$ & $2.71 \pm 0.45$ & $2.91 \pm 0.41$ & $10 \pm 5$ & $(<1$ to 28$)$ \\
\hline (1) & NR & $2.68 \pm 0.27$ & $2.69 \pm 0.26$ & $<1 \pm 2$ & $(-8$ to 11$)$ \\
\hline \multirow[t]{2}{*}{$\mathrm{FEV}_{1} / \mathrm{FVC}$} & $\mathrm{R}$ & $84 \pm 4$ & $89 \pm 5$ & & \\
\hline & NR & $91 \pm 4$ & $91 \pm 4$ & & \\
\hline \multirow{2}{*}{$\begin{array}{l}\mathrm{FEF}_{25-75 \%} \\
(\mathrm{l} / \mathrm{s})\end{array}$} & $\mathrm{R}$ & $2.89 \pm 0.70$ & $3.75 \pm 0.82$ & $33 \pm 9$ & (4 to 49$)$ \\
\hline & NR & $3.43 \pm 0.50$ & $3.73 \pm 0.59$ & $11 \pm 8$ & $(-21$ to 31$)$ \\
\hline \multicolumn{6}{|c|}{ Smokers $($ responders $=9$, nonresponders $=13)$} \\
\hline \multirow{2}{*}{$\begin{array}{l}\mathrm{FEV}_{1} \\
\text { (l) }\end{array}$} & $\mathrm{R}$ & $2.11 \pm 0.31$ & $2.33 \pm 0.34$ & $16 \pm 2$ & (12 to 30$)$ \\
\hline & NR & $2.50 \pm 0.22$ & $2.60 \pm 0.23$ & $4 \pm 1$ & ( -9 to 11$)$ \\
\hline \multirow{2}{*}{$\begin{array}{l}\text { FVC } \\
\text { (l) }\end{array}$} & $\mathrm{R}$ & $2.84 \pm 0.35$ & $2.98 \pm 0.36$ & $6 \pm 2$ & $(-3$ to 21$)$ \\
\hline & NR & $3.23 \pm 0.23$ & $3.35 \pm 0.21$ & $5 \pm 2$ & $(-4$ to 19$)$ \\
\hline \multirow{2}{*}{$\mathrm{FEV}_{1} / \mathrm{FVC}$} & $\mathrm{R}$ & $73 \pm 3$ & $80 \pm 3$ & & \\
\hline & NR & $77 \pm 5$ & $77 \pm 5$ & & \\
\hline \multirow{2}{*}{$\begin{array}{l}\mathrm{FEF}_{25-75 \%} \\
(\mathrm{l} / \mathrm{s})\end{array}$} & $\mathrm{R}$ & $1.74 \pm 0.37$ & $2.56 \pm 0.52$ & $54 \pm 10$ & $(10$ to 105$)$ \\
\hline & NR & $2.69 \pm 0.42$ & $2.91 \pm 0.52$ & $5 \pm 6$ & $(-42$ to 33$)$ \\
\hline
\end{tabular}

Responders $(\mathrm{R})$ are those who had $\geqslant 12 \%$ increase in $\mathrm{FEV}_{1}$; nonresponders (NR), are those who had $<12 \%$ increase in $\mathrm{FEV}_{1}(10)$. All results are expressed as mean \pm SEM. 
nated responders $(\mathrm{R})$ demonstrated a $\geqslant 12 \%$ increase in $\mathrm{FEV}_{1}$ in response to $\mathrm{BD}$ administration. ${ }^{10}$ Five of $12(42 \%)$ patients in the NS group, and 9 of 22 (41\%) members of the $\mathrm{S}$ group demonstrated a significant $\mathrm{BD}$ response.

Linear regression analyses between the level of cervical spinal cord lesion (LOL) and the pulmonary function parameters of $\mathrm{FVC}, \mathrm{FEV}_{1}$, and $\mathrm{FEF}_{25-75 \%}$ before and after $\mathrm{BD}$ administration were performed. In the NS group, the correlation of FVC and $\mathrm{FEV}_{1}$ with LOL is positive and significant prior to administration of $\mathrm{BD}$; the correlation becomes more significant post BD (Table II). However, in the $\mathrm{S}$ group, $\mathrm{FEV}_{1}$ and $\mathrm{FVC}$ failed to significantly correlate with LOL.

\section{Discussion}

Significant improvement of pulmonary function parameters in response to an inhaled bronchodilator strongly suggests the presence of an obstructive component of respiratory dysfunction. In patients with asthma and chronic obstructive pulmonary disease (COPD), airway obstruction is often evident on baseline spirometry, which reveals a decreased $\mathrm{FEV}_{1}$ to $\mathrm{FVC}$ ratio. However, when a restrictive ventilatory impairment is present, as in patients with SCI, the reduced FVC renders interpretation of the $\mathrm{FEV}_{1} / \mathrm{FVC}$ ratio difficult, thereby potentially concealing an obstructive defect.

By assessing pulmonary function before and after $\mathrm{BD}$ administration, we observed

Table II Linear regression analyses between level of lesion and pulmonary function in nonsmokers $(n=12)$

\begin{tabular}{lcclcl}
\hline & \multicolumn{2}{c}{ Pre } & & \multicolumn{2}{c}{ Post } \\
\cline { 2 - 3 } \cline { 5 - 6 } & $r$ & $p$ & & $r$ & \multicolumn{1}{c}{$p$} \\
\hline FVC & 0.59 & 0.04 & & 0.62 & 0.003 \\
FEV $_{1}$ & 0.68 & 0.01 & & 0.72 & 0.0083 \\
FEF $_{25-75 \%}$ & 0.24 & 0.46 & & 0.29 & 0.37 \\
\hline
\end{tabular}

$\mathrm{FVC}=$ forced vital capacity; $\mathrm{FEV}_{1}=$ forced expired volume in 1 second; $\mathrm{FEF}_{25-75 \%}=$ forced expired flow between 25 and $75 \%$ of the exhaled volume. significant improvement in air flow $\left(\mathrm{FEV}_{1}\right)$ in $41 \%$ of the smokers and $42 \%$ of the nonsmokers. Most of the patients demonstrated a disproportionate improvement in $\mathrm{FEV}_{1}$ relative to $\mathrm{FVC}$, thereby increasing the $\mathrm{FEV}_{1} / \mathrm{FVC}$ post BD. Only in retrospect, after administration of $\mathrm{BD}$, can it be suggested that post-BD spirometry reflects the actual degree of restrictive ventilatory impairment due to $\mathrm{SCI}$, whereas in certain patients pre-BD values may represent the superimposition of restrictive and obstructive impairments. We have previously referred to this phenomenon as the unmasking of an obstructive component of respiratory impairment in patients with SCI' ${ }^{11}$ displayed in the pre- and post-BD spirometry in one of the NS patients (Table III). Pre-BD flow rates and an $\mathrm{FEV}_{1} / \mathrm{FVC}$ of 0.80 would be interpreted as quite unremarkable and typical of the restrictive ventilatory impairment resulting from $\mathrm{C} 5-6$ lesion. However, after inhalation of $\mathrm{BD}$, FVC remains unchanged while $F E V_{1}$ increases by $13 \%$, revealing reversal of underlying airway obstruction. The $\mathrm{FEV}_{1} / \mathrm{FVC}$ of 0.90 now reflects the true extent of the restrictive component of this patient and, in retrospect, we are thus able to suggest that the initial $\mathrm{FEV}_{1} / \mathrm{FVC}$ of 0.80 is a reflection of the combination of restrictive and obstructive respiratory impairment. Similarly the strong correlation in the nonsmoker group of $\mathrm{FEV}_{1}$ and $\mathrm{FVC}$ with level of lesion improves post $\mathrm{BD}$ (Table II), probably as a consequence of elimination of the obstructive impairment, which then allows the SCIinduced restrictive impairment to be measured without other superimposed variables. The variable obstructive component in the smoker group presumably obscures this relationship.

Of particular interest is the significant BD response observed in 5 of $12(42 \%)$ nonsmoking patients, who had no history of pulmonary disease or respiratory symptoms prior to their injury. These data suggest that the cervical lesion itself causes some degree of airflow obstruction, most likely secondary to the interruption of sympathetic innervation to the lung and the resultant unopposed parasympathetic tone of the bronchial smooth musculature. 
Table III Pre- and post-BD spirometry in a nonsmoking patient

\begin{tabular}{|c|c|c|c|c|c|c|c|}
\hline \multicolumn{8}{|c|}{ Sample subject: bronchodilator data } \\
\hline \multirow{4}{*}{\multicolumn{2}{|c|}{$\begin{array}{r}\text { Age } \\
\text { Sex/Race } \\
\text { Height } \\
\text { Weight }\end{array}$}} & \multirow{4}{*}{\multicolumn{2}{|c|}{$\begin{array}{l}42 \text { years } \\
\text { Male/Black } \\
70 \mathrm{in}, 178 \mathrm{~cm} \\
165 \mathrm{lb}, 75 \mathrm{~kg}\end{array}$}} & \multirow{4}{*}{$\begin{array}{r}\text { Diagnosis } \\
\text { Dyspnea } \\
\text { Cough } \\
\text { king history }\end{array}$} & \multicolumn{3}{|c|}{ C5-6, incomplete quadriplegia } \\
\hline & & & & & & for $6 \mathrm{yr}$ & \\
\hline & & & & & & & \\
\hline & & & & & & & \\
\hline \multirow[b]{2}{*}{ Spirometry } & & \multirow[b]{2}{*}{ Pred } & \multicolumn{2}{|c|}{ Pre BD } & \multicolumn{2}{|c|}{ Post BD } & \multirow[b]{2}{*}{$\% \Delta$} \\
\hline & & & Best & $\%$ Pred & Best & $\%$ Pred & \\
\hline FVC & (l) & 5.07 & 3.72 & 73 & 3.73 & 73 & $<1$ \\
\hline FEV1 & (l) & 3.84 & 2.97 & 77 & 3.35 & 87 & 13 \\
\hline FEV1/FVC & $(\%)$ & 75 & 80 & & 90 & & \\
\hline $\mathrm{FEF}_{25-75 \%}$ & $(\mathrm{l} / \mathrm{s})$ & 3.91 & 2.62 & 67 & 3.89 & 99 & 48 \\
\hline $\mathrm{FEF}_{50 \%}$ & $(1 / s)$ & 5.08 & 2.78 & 55 & 4.12 & 81 & 48 \\
\hline $\mathrm{PEF}$ & $(1 / s)$ & 9.25 & 6.65 & 72 & 7.58 & 82 & 14 \\
\hline
\end{tabular}

$\mathrm{FEF}_{50 \%}=$ forced expiratory flow at $50 \%$ of exhaled volume; PEF = peak expiratory flow.

Our results suggest that, in addition to the well documented restrictive ventilatory impairment associated with quadriplegia, an obstructive component of respiratory dysfunction may result from transection of the cervical spine. In cervical SCI patients with respiratory symptoms otherwise unexplained, pre- and post-BD pulmonary function testing may demonstrate the presence of latent airway obstruction. A therapeutic trial of an inhaled beta-adrenergic agent is warranted in this situation, regardless of the presence of a significant BD response during formal testing, since the sensitivity of the test in this population is not known.

To further investigate the hypothesis that unopposed parasympathetic tone is responsible for cervical SCI-induced airway obstruction, bronchoprovocation challenge testing with an acetylcholine analog should be performed.

\section{References}

1 Mansel JK, Norman JR (1990) Respiratory complications and management of spinal cord injuries. Chest 97 : 1446-1452.

2 Bergofsky EH (1964) Mechanism for respiratory insufficiency after cervical cord injury. Ann Intern Med 61: 435-447.

3 Ohry A, Molho M, Rozin R (1975) Alterations of pulmonary function in spinal cord injured patients. Paraplegia 13: 101-108.

4 Forner JV, Llonbart RL, Valleder MCV (1977) The flow-volume loop in tetraplegics. Paraplegia 15: 245-251.

5 McMichan JC, Michel L, Westbrook PR (1980) Pulmonary dysfunction following traumatic quadriplegia. JAMA 243: 528-531.

6 Ledsome JR, Sharp JM (1981) Pulmonary function in acute cervical cord injury. Am Rev Respir Dis 124: 41-44.

7 Polatty RC, McElaney MA, Marcelino V (1987) Pulmonary complications in the spinal cord injury patient. Arch Phys Med Rehabil 1: 353-373.

8 Barnes PJ (1986) Neural control of human airways in health and disease. Am Rev Respir Dis 134: 1289-1314.

9 American Thoracic Society. (1987) Standardization of spirometry - 1987 update. Am Rev Respir Dis 136: 1285-1298.

10 American Thoracic Society (1991) Lung function testing: selection of reference values and interpretive strategies. Am Rev Respir Dis 144: 1202-1218.

11 Dicpinigaitis PV, Spungen AM, Yoo OH, Bauman WA (1991) Bronchodilators unmask the obstructive component of respiratory dysfunction in patients with paralysis. J Am Para Soc 14: 192. 